\title{
0 que se aprende além das letras: um estudo sobre a alfabetização de pessoas idosas
}

\section{What isleamed beyondletters. astudy abat alphabetization of eddely}

Com o objetivo de refletir sobre a importância da manutenção de espaços educativos que atendam às necessidades e desejos de pessoas idosas que têm interesse de participar de ações educativas não-formais, este artigo apresenta alguns dos resultados obtidos em pesquisa de Mestrado conduzida pela metodologia de pesquisa-formação História de Vida, realizada com um grupo de sete educandas idosas, com idades entre 60 e 73 anos, do Programa Movimento de Alfabetização de Jovens e Adultos - MOVA-Guarulhos. Expõe e analisa as razões pelas quais tais sujeitos não se alfabetizaram em outras fases da vida e resolveram, na fase idosa, integrar um núcleo de alfabetização onde convivem com pessoas de todas as faixas etárias acima dos 16 anos. Evidencia as conquistas observadas pelos próprios sujeitos diante de suas experiências como pessoas em processo de alfabetização, muitas delas que extrapolam o âmbito da aprendizagem da leitura e da escrita, especialmente aquelas relacionadas ao desenvolvimento da oralidade e os ganhos na convivência social dela decorrente de variadas formas. Conclui que a frequência ao núcleo de alfabetização contribui para a formação do sujeito, proporcionando algumas conquistas pessoais que não são diretamente relacionadas com o domínio da leitura e da escrita - fato que deve ser considerado para o aprimoramento das ações educativas voltadas ao público idoso.

\section{Abstract}

This paper aims to reflect about the importance to support educative spaces able to meet the needs and desires of elderly people interested in taking part in nonformal education. It introduces some results obtained from a Masters Degree Research, guided by History of Life as research-formation methodology,

Área de Fundamentos da Educação. Universidade Federal de Viçosa - Campus Florestal. Florestal, MG, Brasil.

Correspondência / |Correspondence

Patrícia Claudia da Costa

Rodovia LMG, 818 - km 6

35690-000 Florestal, MG, Brasil

E-mail: patricia.claudia@ufv.br

Patrícia Claudia da Costa ${ }^{1}$

Palavras-chave:

Aprendizagem. Motivação.

Educação. Idoso.

Alfabetização. 
accomplished with a group of seven aged students with ages between 60 to 73 years old, from an Alphabetization Program called Alphabetization of Young and Adults Movement - MOVA-Guarulhos. It presents and analyzes the reasons why the subjects did not learn to write and to read in earlier phases of life as also as they decided, in the aged phase, to join an alphabetization nucleus where they are interact with people of all ages from 16. It evidences the observed conquests by the subjects when they evaluate their experiences as people in alphabetization process, many conquests that extrapolate the scope of learning to read and to write, specially that ones in the relation to the development of orality and its current advantages in sociability. It concludes that the participation in the alphabetization nucleus contributes to the formation of the subject, providing some personal conquests that are not directly linked to the appropriation of reading and writing - a fact to be considered in the elaboration of educational actions for the elderly.
Key words: Learning. Motivation. Education. Aged. Alphabetization.

\section{INTRODUÇÃO}

Este artigo pretende apresentar, aos interessados em questões relacionadas ao campo da Educação no âmbito da Gerontologia, algumas descobertas realizadas a partir de pesquisa de mestrado realizada no Programa de PósGraduação da Faculdade de Educação da Universidade de São Paulo, entre 2005 e 2008, tendo como objeto a motivação de pessoas idosas para frequentar um movimento de alfabetização de jovens e adultos. Da ampla base de dados obtidos, serão discutidos recortes que explicitam como os sujeitos se aproximaram e se engajaram num movimento de educação popular após os 60 anos de idade, data considerada como início da fase idosa da vida humana. Por que não estudaram antes? Por que procuraram um núcleo de alfabetização agora? Como chegaram a esse núcleo? Por que um núcleo de educação popular e não uma escola formal? Essas serão as principais questões aqui debatidas.

O objetivo é trazer a público uma oportunidade de reflexão sobre a importância da manutenção de espaços educativos que atendam às necessidades e desejos de pessoas que não têm mais interesse na escolarização formal - por não carecerem de certificados e seus corolários, e muito menos se adaptarem aos moldes de organização do cotidiano escolar - e, contudo, encontram em experiências de educação nãoformal a chance de desenvolver diversos aspectos da formação humana, inclusive indo além do fim específico da alfabetização.

\section{0 grupo em estudo}

Essa realidade não pode ser pensada isoladamente do contexto geográfico e político que vivemos. De acordo com a Declaração Final da Conferência Regional América Latina e Caribe, preparatória para a VI Conferência Internacional de Educação de Adultos (CONFINTEA), esta é a região mais desigual do mundo pelo fato de ser habitada por 71 milhões de pessoas vivendo na indigência e cerca de 200 milhões de pobres. $\mathrm{O}$ documento afirma que qualquer ação educativa voltada para pessoas que não se escolarizaram na idade própria está situada na problemática da indissociável exclusão educativa e política, econômica e social. Por isso, a educação deveria estar a serviço da luta contra a pobreza e a exclusão social, mesmo reconhecendo que o combate às exclusões não se esgotam no campo educativo, mas dependem de mudanças estruturais e convergência de outras políticas cuja discussão foge ao escopo do presente artigo. ${ }^{1}$

Contudo, não podemos deixar de destacar uma característica marcante do segmento populacional estudado por meio da amostra que colaborou com a pesquisa. Referimo-nos à situação de pobreza comum ao grupo e ao impacto provocado por essa situação na constituição das subjetividades que o compunham. A percepção 
de como as condições objetivas de sobrevivência contribuem para a precarização do envelhecimento e para a construção $d a$ autoimagem dos indivíduos em situação de exclusão social, foi exposto por Simone de Beauvoir, no início dos anos 70 do século passado, em sua seminal obra sobre a velhice: "Nenhum estudo [ref. às disciplinas isoladamente] nos permitirá definir a velhice; constataremos, ao contrário, que ela assume uma multiplicidade de aspectos, irredutíveis uns aos outros. Tanto ao longo da história como hoje, a luta de classes determina a maneira pela qual um homem é surpreendido pela velhice; um abismo separa o velho escravo e o velho eupátrida, um antigo operário e um Onássis. A diferenciação das velhices individuais tem ainda outras causas: saúde, família etc. Mas são duas categorias de velhos (uma extremamente vasta, e outra reduzida a uma pequena minoria) que a oposição entre exploradores e explorados cria. Qualquer afirmação que pretenda referir-se à velhice em geral deve ser rejeitada porque tende a mascarar este hiato." ${ }^{\text {(p. 17) }}$

Interessa-nos especialmente, na obra $\mathrm{da}$ escritora francesa, o destaque atribuído à divisão de classes como o elemento fundante das diferenças entre as pessoas idosas, enquanto grupo etário, e entre os demais indivíduos, enquanto ocupantes de lugares sociais, pois percebemos que os sujeitos pesquisados também manifestaram a compreensão de que: pessoas em situação econômico-social privilegiada gozam de um envelhecimento mais saudável e tranquilo; as dificuldades impostas pelo lugar social que ocupam contribuíram para culminância da dureza dos dias atuais; e, finalmente, as pessoas em situação socioeconômica desfavorecida têm reduzidas chances de envelhecimento digno, chegando inclusive a envelhecer mais rapidamente. Ouvimos literalmente de nossas colaboradoras:

"Depende muito de pessoa prapessoa... Quem tem dinheiro, pode ter até 80 anos e ninguém dir que é idoso...".

De certa forma, essa já era a idéia de Beauvoir ao afirmar que "é na última idade que se cava mais profundamente o fosso entre os privilegiados e a imensa maioria dos homens".2 (p. 662). Isto porque o fosso já vem sendo cavado ao longo do tempo e a sucessão dos anos vem sendo utilizada a serviço da desvalorização dos sujeitos em situação de exclusão social, desde o berço, ao invés de se prestar como prova de acumulação de méritos e de construção da dignidade humana. Portanto, nessa fase da existência humana: "Quando estão cansados de sua profissão, de sua vida, certos indivíduos se dizem velhos, embora seu comportamento não seja o de uma pessoa idosa. [...] Para um homem que está satisfeito consigo mesmo e com sua condição, e que tem boas relações com os que o cercam, a idade permanece abstrata." ${ }^{2}$ (p. 360)

Não identificamos nenhuma abstração no grupo estudado. Pelo contrário, as narrações de história de vida revelaram que o fato de ser um sujeito idoso é vivido como um obstáculo ao acesso do direito à educação. No entanto, os sujeitos perseveravam na frequência às aulas e com isso apontavam que as conquistas relacionadas ao desenvolvimento da oralidade são consideradas como superiores àquelas diretamente relacionadas ao aprendizado da leitura e da escrita, ao avaliar seus desempenhos ao longo da participação no núcleo de alfabetização. Este dado se constitui como um significativo achado, na medida em que deixa de corroborar hipóteses comumente utilizadas em pesquisas com alfabetizandos adultos, as quais indicam desejos ou necessidades de uso da leitura e da absolutamente escrita como principal motor de permanência dos sujeitos em ações alfabetizadoras. Essa era uma de nossas hipóteses iniciais, francamente destruída, conforme veremos a seguir.

\section{METODOLOGIA}

Foi utilizada a metodologia de pesquisaformação "História de Vida", uma abordagem qualitativa que, de acordo com observações de uma de suas precursoras, ${ }^{3}$ destaca-se pelo fato de o pesquisador suscitar recordações de experiências significativas em relação ao questionamento que orienta a narrativa dos sujeitos envolvidos. $\mathrm{O}$ 
trabalho proposto por Josso ${ }^{3}$ é composto por diversas etapas. Num primeiro momento, cabe ao responsável pela pesquisa mediar momentos de narração de experiências pessoais (de acordo com temas e eixos predeterminados). Ele deve ter em mente que a escuta das narrativas pretende garantir que os sujeitos colaboradores da pesquisa possam expor todo tipo de informação sobre suas vidas. Numa fase mais adiantada do trabalho, o conjunto de informações, após cuidadosa análise por parte da pesquisadora e dos sujeitos pesquisados, é utilizado como elemento de construção das respostas exigidas pelo objeto a ser investigado.

A importância da metodologia de pesquisa e de formação autobiográfica reside, fundamentalmente, na característica de constituirse como meio de proporcionar aos sujeitos que dela participam a oportunidade de vivenciarem, simultaneamente, o papel de sujeito e de objeto de sua formação. ${ }^{3}$ Assim, os sujeitos em situação de processo formativo expuseram suas experiências de vida de modo que suas realidades se desvelassem, paulatinamente, conforme o grupo elaborava, com a mediação da pesquisadora, a percepção de que as histórias de vida não consistem numa sucessão de acasos, mas em um sistema de ações e reações pelas quais todos nós somos responsáveis ou, pelo menos, co-participantes.

A amostra foi composta por sete estudantes com idade entre 60 e 73 anos que participavam de um núcleo de alfabetização do Programa Movimento de Alfabetização de Jovens e Adultos - MOVA-Guarulhos, onde também estudavam outros oito alfabetizandos cujas idades variavam de 16 a 55 anos.

Os encontros de construção de História de Vida ocorreram nas dependências da Comunidade Santa Teresa D’Ávila, uma igreja católica na qual o núcleo se instalava na periferia guarulhense. A duração de cada um dos 19 encontros semanais foi de aproximadamente $1 \mathrm{~h} 30 \mathrm{~min}$, durante o horário das aulas que aconteciam das $8 \mathrm{~h}$ às $10 \mathrm{~h} 30 \mathrm{~min}$, de segunda a quinta-feira. A duração e o horário foram negociados junto ao grupo e a sua educadora, considerando as disponibilidades de todos os envolvidos no trabalho. Os encontros foram registrados em fitas de áudio, posteriormente submetidas a transcrição e análise, de modo que cada uma das 19 reuniões gerou um respectivo relatório de pesquisa.

Além dos encontros semanais, o grupo também participou de três atividades externas e concedeu, ao final do trabalho de campo, entrevistas individuais com duração média de uma hora. Todos os sujeitos envolvidos aprovaram e assinaram um termo de consentimento livre e esclarecido para divulgação das informações registradas em áudio, imagem e texto escrito (disponível para consulta em Costa, 2008). ${ }^{4}$ Os procedimentos foram aprovados pelo Parecer 004/2011, emitido pelo Comitê de Etica da Faculdade de Educação da Universidade de São Paulo.

Neste artigo, os depoimentos dos sujeitos são destacados em fonte itálica, sem identificação individual mas com referência da dissertação da qual foram extraídos.

\section{RESULTADOS}

Abordaremos como e por que os sujeitos pesquisados participam de uma ação alfabetizadora na fase da vida marcada pelo ser idoso e quais são as conquistas decorrentes dessa participação. Primeiramente, destacamos que todas as colaboradoras nasceram e cresceram em ambientes rurais nos quais a escola nem sempre existia. Quando havia, o acesso era dificultado pela distância, necessidade de ajudar no trabalho da roça familiar, desconfiança dos pais que não admitiam que meninas e meninos estudassem juntos e até pelo medo de apanhar do professor. Desse modo, poucos sujeitos tiveram a oportunidade de frequentar uma sala de aula quando criança ou adolescente, cabendo ao grupo a marca da heterogeneidade quanto ao modo e tempo de ingresso em experiências de alfabetização.

O conjunto de histórias de vida narradas revelou que as demandas cotidianas de interação social em ambiente urbano foram um motor 
importante para induzir uma experiência de alfabetização. Isso nos levou a questionar: se o desejo ou a necessidade de estudar foram percebidos desde a adolescência (em situações de impossibilidade de comunicação por meio de cartas e de interação nas raras oportunidades de convivência urbana) e aprofundada na idade adulta, com a mudança definitiva para um ambiente urbano repleto de desafios impostos pelas necessidades de locomoção e de diversos tipos de comunicação, por que essas senhoras demoraram tanto tempo para começar a estudar?

Todas as colaboradoras destacaram que atualmente as oportunidades para estudar são muito maiores do que na época de suas mocidades. Eram recorrentes os comentários:

'Depois que esse prefeito entrou, tem escola pra todo mundo. Antes, não tinha! Ave-Maria! Tinha bairro que nem as crianças tinham onde estudar. Agora, em qualquer lugar tem MOVA: só não estuda quem não quer! ${ }^{4}$

Contudo, suspeitávamos que a escassez de oportunidades para dar início ou continuidade aos estudos em uma ação educativa voltada para a Educação de Jovens e Adultos, historicamente reconhecida em nosso país, não poderia ser a única causa de o ingresso numa sala de aula ter sido tão postergado.

Em várias abordagens da questão, uma ideia sempre se mostrou muito marcante nas narrativas: a presença do marido como inibidor $d a$ escolarização. A dominação manifestou-se de formas parecidas que podem ser resumidas no seguinte enredo: os filhos pequenos precisam de cuidados que os maridos se recusam a oferecer; quando aqueles crescem um elemento secundário de outrora entra em cena na expressão da inconveniência de uma "mulher de família" (sic) sair de casa à noite para ir à escola.

O peso da dominação masculina há de ser considerado para compreendermos a trajetória de vida dessas mulheres. No grupo havia cinco viúvas e duas casadas e eram exatamente essas que enfrentavam os maiores apuros no que diz respeito à falta de incentivo familiar para frequentar o núcleo de alfabetização, conforme analisado em outro artigo. ${ }^{5} \mathrm{E}$ por que escolher uma sala de aula num movimento de alfabetização, em funcionamento dentro de uma igreja, e não de uma escola formal?

Um diferencial apontado pela maioria dos sujeitos é o fato de a entrada em um movimento de alfabetização geralmente acontecer a partir de um convite pessoal, como um aviso ao final $\mathrm{da}$ missa ou convite feito diretamente pela educadora ou alguma colega que já esteja estudando. Este é um primeiro sinal de acolhida do movimento que impulsiona as pessoas para o integrarem. Além disso, há a questão da proximidade da residência das estudantes em relação ao local onde as aulas são oferecidas, o horário diferenciado (no município de Guarulhos não havia nenhuma sala de aula formal para alfabetização de adultos no horário matutino) e a presença de pessoas amigas na composição da turma de alfabetização, especialmente a própria alfabetizadora, figura popular no bairro. Todos esses fatores indicam uma condição de acolhimento que favorece a permanência das pessoas idosas no núcleo de alfabetização.

Para engrossar o caldo de predileção pela educação não-formal, alguns casos foram apontados para ilustrar a rejeição à escola formal por características que lhe são peculiares. Entre os sete sujeitos pesquisados, três declararam ter tido ou acompanhado experiências em que a desistência da escolarização formal ocorreu devido à incompatibilidade de ritmos na relação ensinoaprendizagem entre educador e educandos lousas cheias de tal modo que os alunos sequer conseguiam copiar a lição até o final da aula, explicações aligeiradas e pouco esclarecedoras, conteúdos não pertinentes para o nível de desenvolvimento cognitivo dos indivíduos etc. Houve ainda uma denúncia ao clima de falta de solidariedade intergeracional:

"Osjovens de hoje tiram sarro dos idosos: deveria ter sempre uma sala de aula para os idosos nem que fosse um borário diferente." ${ }^{4}$ 
Já em relação às aulas vivenciadas no MOVA, as queixas incidem sobre o excessivo treino $\mathrm{da}$ Matemática e o baixo nível de desafio das atividades de leitura e escrita após o ingresso de alfabetizandos em níveis iniciais de construção da escrita:

"Gostava mais de quando tinha menos alunos: agora, as lições estão muito fáceis. "4

Vale destacar que todos os sujeitos pesquisados já estudavam no MOVA no mínimo por um ano e cinco deles já haviam passado por outros núcleos, em outros horários e locais. Invariavelmente, a opção pelo núcleo explicavase pela afinidade com a educadora e os colegas, assim como pela disponibilidade do horário e aprovação pessoal do conteúdo e da metodologia desenvolvidos pela educadora popular. A estudante com mais longa participação no movimento totalizava quatro anos de frequência ao núcleo de alfabetização, marcados por interrupções provocadas por problemas de doença e falecimento na família.

A perseverança pode ser considerada como uma marca característica do grupo estudado. Não raros foram os relatos de situações em que se fizeram nítidas as estratégias de persistência e valorização do fato de ter se tornado estudante, mesmo que a tentação da desistência seja um fantasma não raramente presente:

"Iá pensei em sair da escola porque não estou aprendendo: o tempo que estou aqui, eu aprendi muito pouco as coisas." ${ }^{\prime 4}$

No entanto, os relatos de superação e persistência prevalecem sobre as manifestações de desânimo, como no caso de duas senhoras que sofreram grandes perdas familiares e voltaram a estudar logo após como forma de amenizar a solidão do lar, conforme as narrativas coletadas.

Ao serem solicitadas a autoavaliar seu desempenho como estudante, as alfabetizandas foram, em geral, rigorosas e modestas. Apenas uma declarou:

Já aprendi bastante coisa. Estou ficando mais sabida. $E$ en acho que as pessoas percebem. ${ }^{4}$
As demais foram comedidas ao apontar que ainda se encontram envoltas em dificuldades para ler e escrever.

Por outro lado, cinco diferentes sujeitos ${ }^{4}$ apontam como avanço:

"Antes eu não sabia os nomes dos produtos nos folhetos do mercado. Agora vem o dia que aquela oferta vale. Quem não sabe lerpode comprar tudo no dia errado. Isso acontecia muito com a gente. Ainda não consigo ver bem o dia da oferta. Tem que prestar muita atenção para não errar. Mas já consigo entender aquilo tudo bem melhor."

"Agora eu leio e escrevo tudo o que precisa nas reuniōes da igreja. Antes eu nem assinava meu nome na lista de presença, era uma vergonha: tinha que esperar a reunião acabar e pedir pra alguém assinar pra mim. E hoje sou eu quem assina para as minhas colegas que não quiseram vir estudar. Eu já deixo um bilhete para avisar alguma coisa para a minha filha quando preciso sair de casa. E uso o telefone, coisa que eu não sabia como é que achava os números para ligar."

"Pouco a pouco, en estou perdendo o medo de falar. Na alfabetizaşão eu aprendi a falar melhor."

"Já entendo coisas que antes precisaria perguntar."

"Men filho fala que en era braba atépara conversar! Eu digo que não ébraba, é que eu não sei ler; então, en ficava braba quando falava as coisas e não falava direito. Eles davam risada, brincando comigo e eu ficava chateada. Hoje eu mudei muito...."

Diante do avaliado, restou-nos aprofundar o questionamento: "além das letras, o que a alfabetização está lhe proporcionando?” Obtivemos como resposta: ${ }^{4}$

"Liberdade de sair e conversar com as pessoas."

"Eu acho que o maior avanco nisso tudo foi conhecer maispessoas."

"Aprendi falar melhor, não tenho mais vergonha de conversar na frente dos outros."

"Me trouxe companbia, o que eu mais precisava quando perdi meu esposo." 
"Amizades: na escola, a gente conversa, se comunica. Porque a coisa pior que tem é, às vezes, a pessoa ficar em casa sozinba."

"Superei a vergonha de me expor, de conversar assim no público. Aprendi bastante coisa, né? Estou ficando mais sabida."

\section{DISCUSSÃO}

Ao longo das leituras que realizamos, comprovamos que as dificuldades apontadas não constituem uma novidade no cenário educacional brasileiro. Ao estudar o preconceito contra o analfabeto, Galvão \& Di Pierro ${ }^{6}$ analisaram a precariedade de acesso à educação no Brasil desde os tempos coloniais: uma história de reduzidas oportunidades de escolarização, sobretudo nas áreas rurais, o que restringia o direito à educação a uns poucos homens livres ambientados nas vilas e cidades. Enquanto isso, o discurso oficial pretendia imputar aos próprios indivíduos compulsoriamente excluídos da escola a responsabilidade sobre os alarmantes índices de analfabetismo da nação: "A historiografia tradicional atribui os elevados índices de analfabetismo da sociedade brasileira desses tempos a uma suposta indiferença da população rural, então majoritária, pela escola. Esse, talvez, seja mais um sintoma do preconceito que tende a responsabilizar os analfabetos por sua condição, já que há evidências e documentos históricos que demonstram que a população do campo tinha, sim, interesse pelo estudo, ficando os pobres (e os escravos em especial) dele afastados pela falta de professores ou de escolas que pudessem frequentar. [...] Não é, pois, de se estranhar que os índices de analfabetismo só tenham começado a recuar no século XX, quando se intensificou a migração do campo para as cidades e começou a se estruturar uma rede de escolas públicas acessível à população mais pobre, ao mesmo tempo em que se desenvolveram campanhas de alfabetização de adultos. Devido ao crescimento acelerado da população, porém, o número absoluto de analfabetos cresceu continuamente, e só começou a declinar no final do século XX”. ${ }^{6}$ (p. 57-58)

Vemos, assim, que as justificativas apresentadas pelos sujeitos desta pesquisa para o fato de não terem frequentado a escola "em idade própria" se inscrevem num contexto historicamente reconhecido como marca do processo de civilização imposto ao país: em todas as regiões e, sobretudo, nas áreas essencialmente rurais, o acesso à escola foi largamente negado às populações pauperizadas, alimentando um ciclo de desigualdade de oportunidades de inserção social que caracteriza o Brasil até os dias atuais.

No presente caso, tratamos de um grupo de mulheres de baixa renda, a maioria sobrevivendo com uma pensão conquistada pela perda do esposo, quase todas as pensões no valor de um salário mínimo. A vida social dessas mulheres basicamente se restringe à participação no MOVAGuarulhos e às atividades religiosas oferecidas pela comunidade católica que acolhe o núcleo de alfabetização. Passam a maior parte do tempo em casa, cumprindo o desafio de ficar sozinha ou cuidar dos netos. Quando saem de casa, hospitais públicos são o destino mais corriqueiro. As raras oportunidades de passeios são oferecidas pela Igreja (visita a santuários ou retiros), o que tornou as atividades externas, que compuseram o conjunto de estratégias de coleta de dados desta pesquisa, algo muito especial na formação cultural de cada uma delas.

O universo de pessoas estudado, marcado pela precariedade das condições de subsistência, se inscreve na caracterização do sujeito oprimido formulada por Paulo Freire. ${ }^{7,8}$ Falamos de seres históricos: sete mulheres que "estão sendo" num mundo onde a opressão se manifesta de diversas maneiras. Quando crianças, foram oprimidas pelos pais, que não facilitaram o acesso à escolarização. Os pais, por sua vez, constituíramse enquanto sujeitos também imersos na opressão típica dos meios rurais no início do século XX.

O direito à educação foi apenas um dos negados dentre uma ampla lista assegurada pelas leis que regem a sociedade em que vivemos. Com a saída da opressão vivida durante a infância e a adolescência na casa dos pais, um segundo tipo é inaugurado pelo casamento como libertação do jugo paterno e nova forma de tolhimento social. Todas as senhoras participantes da pesquisa viveram casadas durante mais da metade do seu 
tempo de vida. A maioria dos relatos sobre a relação com o esposo revelou ressentimentos decorrentes da forma de tratamento imposta, marcada pela opressão manifesta no controle das finanças, de seus corpos e seus comportamentos. Não raramente os esposos - com baixo nível de escolarização, porém superior ao da mulher lançavam mão de comentários perniciosos sobre a condição de analfabetismo para ridicularizar, inferiorizar e, assim, justificar sua posição de comando nas decisões familiares.

E não é apenas o ambiente familiar, da casa do pai à casa do esposo, que surge nas histórias de vida como palco de opressão. Fora de casa, ela aparece ainda com mais vigor na forma da discriminação sofrida pelos sujeitos reconhecidos como "incapazes" de compreender a língua escrita. Os numerosos casos de humilhação narrados são provas mais que evidentes da insensibilidade que permeia nossa sociedade no que diz respeito à forma de tratamento sofrida pelas pessoas que não dominam a leitura e a escrita.

Cientes de todas essas instâncias opressoras, os sujeitos se refugiam na "cultura do silêncio". O silêncio inscreve-se no bojo da vergonha de si costumeiramente presente nos relatos, fruto do encontro dos sentimentos de inferioridade e de exposição. Em função da vergonha, muitos dos sujeitos haviam se isolado do convívio social até se engajarem no MOVA-Guarulhos. Portanto, de acordo com a avaliação das educandas, a frequência ao núcleo de alfabetização tem facilitado sobremaneira a destruição da vergonha de si, na medida em que oferece condições para o desenvolvimento de habilidades que influenciam diretamente no isolamento imposto pela vergonha que provoca o sentimento de ser-menos. O falar é a principal delas.

Inicialmente interessadas na investigação dos motivos para a alfabetização, certamente nos surpreendemos ao perceber que a alfabetização estritamente dita não se constituía enquanto principal fonte de motivação para a permanência no núcleo de alfabetização. Ela pode até ter sido o motivo principal da entrada no núcleo. Contudo, a oportunidade de convivência num grupo etariamente heterogêneo, unido em torno da escrita enquanto objeto de conhecimento a ser construído por todos, convivência esta permeada por situações facilitadoras do desenvolvimento da oralidade numa perspectiva não-estigmatizante, desponta para o grupo estudado como um elemento essencial na explicação do "por que estamos aqui". Nesse sentido, afirmamos que a motivação para a frequência ao núcleo de alfabetização se deve menos ao aprendizado da língua escrita que à oportunidade de interação social. Caso contrário, como compreender declarações do tipo:

"Enquanto tiver MOVA, estarei aqui. Espero que dure, pelo menos, mais uns dez anos..." ou "A melhor coisa que o MOVA trouxe para a minha vida foram as amizades", ou ainda "Eu venho estudar porque é melhor do que ficar sozinha em casa?"

\section{CONCLUSÕES}

Diante de tais alegações, nossas considerações finais assumem a ampliação das hipóteses iniciais da pesquisa, que supunham como motivação para a entrada ou retorno em oportunidades de escolarização o fato de o adulto ou idoso desejar ler a Bíblia, locomover-se na cidade, comunicarse por meio da escrita, ajudar os filhos ou netos na escola, tomar conta dos próprios negócios e tantas outras necessidades impostas pela sociedade grafocêntrica, também apontadas por nossas colaboradoras. Não negamos a existência desses fatores como componentes da motivação; no entanto, ao contrário do que muitos poderiam esperar, eles não são o ponto fundamental.

A autoavaliação dos avanços obtidos no campo da comunicação oral orienta os sujeitos estudados para a declaração de que tomar a conquista da alfabetização, estritamente dita, como a principal motivação para a participação num movimento popular de educação, equivale a reduzir ingenuamente um universo muito amplo de atribuições de sentido ao ato de estudar. Destacamos uma reveladora síntese elaborada por uma das senhoras participantes na pesquisa:

"Eu era uma pessoa discriminada, que vivia presa dentro de casa, que não sabia nem conversar direito 
com as pessoas. Hoje sou livre, não sou presa dentro de casa, já converso. Não abertamente porque muitas palavras en tropico. Tem palavra que en não consigo falar direito porque tenho a lingua pregada. Ninguém acredita, mas eu tenho. As palavras que en sei que eu não consigo falar direito eu nem quero pronunciar porque tenho medo de falar errado e ser caçoada. Ponco a pouco, en eston perdendo o medo de falar. Na alfabetização en aprendi a falar melbor e agora eu não tenho mais vergonha de conversar na frente dos outros. Até agora, eu consegui superar poucas dificuldades de leitura e de escrita: ler eu não consegui ainda, $e$ escrever tenho que copiar. Ainda não me considero uma pessoa alfabetizada, mas pelo menos já consigo me virar sozinha. E eu sei que, se não estivesse no MOVA, não teria vivido coisas tão gratificantes." (p. 133)

O emaranhado de motivos que sustentam a participação no programa de alfabetização nos remete à relação entre aprendizagem e identidade: "Se a língua determina parte de nossa identidade, há motivos para que negociemos o que queremos ou não aprender. $\mathrm{O}$ aprendizado da escrita inclui uma outra cultura e uma outra linguagem diferente da oral, embora com ela relacionada." ${ }^{8}$ (p. 158)

Para os sujeitos estudados, a negociação passa diretamente pela redescoberta da linguagem oral como possibilidade de reconstrução identitária. Dito de outro modo, aprender a ler e a escrever é inegavelmente importante; contudo, situar-se no mundo como sujeito portador de uma fala não-estigmatizada é algo tão valioso quanto mostrar-se publicamente como um sujeito alfabetizado.
Insistimos no fato de que o domínio da leitura e da escrita também é um desejo acalentado pelos sujeitos da pesquisa. Contudo, a frequência ao núcleo de alfabetização traz muitas outras vantagens que não passam despercebidas por quem está cansada de ser reconhecida e humilhada como analfabeta "até pelo jeito de falar".

De todo o exposto, podemos chegar a algumas conclusões provisórias: o acesso ao código escrito não é a principal fonte de motivação para a permanência de alguns educandos, as conquistas no campo da oralidade podem sobrepujar os avanços ligados diretamente à língua escrita e, o que parece mais instigante, as ações promovidas na área da Educação de Jovens e Adultos precisam levar em conta essa realidade. Muito ainda há de se investigar nesta problemática: o que as pessoas idosas esperam da alfabetização? Como a educação - formal e não-formal - pode atender às suas expectativas? Essas são questões fundamentais para alimentar o avanço de ações que atendam satisfatoriamente a pessoas idosas que buscam por alfabetização. Mesmo que, e especialmente se, uma busca que vá além das letras.

\section{AGRADECIMENTOS}

À Secretaria Municipal de Educação de Guarulhos, especialmente à Equipe de Coordenação do MOVA-Guarulhos, pela manutenção do Movimento que ofereceu o mais profícuo cenário para o estudo proposto.

À Profa. Dra. Nilce da Silva, da Faculdade de Educação da USP, pela cuidadosa orientação da pesquisa. 


\section{REFERÊNCIAS}

1. UNESCO. Educação e aprendizagem para todos: olhares dos cinco continentes. Brasília: UNESCO; 2009.

2. Beauvoir S. A velhice. Rio de Janeiro: Nova Fronteira; 1990.

3. Josso MC. Experiências de vida e formação. São Paulo: Cortez; 2004. 288 p.

4. Costa PC. Sem medo de ser falante: as conquistas da oralidade por educandas idosas no MOVA-Guarulhos. São Paulo. Dissertação [Mestrado em Educação]-Faculdade de Educação da Universidade de São Paulo; 2008.

5. Costa PC. Além de mulher, velha, além de velha, mulher: relatos de educandas idosas do MOVA-Guarulhos. In: Anais do 15. Encontro
Nacional de Didática e Prática de Ensino. 2010 jul 15-18; Belo Horizonte, Brasil. Belo Horizonte: UFMG, FAE; 2010.

6. Galvão AMO, Di Pierro MC. Preconceito contra o analfabeto. São Paulo: Cortez; 2007, 120 p.

7. Freire P. Pedagogia do oprimido. 43.ed. Rio de Janeiro: Editora Paz e Terra; 2005. 213 p.

8. Freire P. Ação cultural para a liberdade. 5.ed. Rio de Janeiro: Paz e Terra; 1981. 149 p.

9. Pereira LE. O nascimento do estranho na cidade de São Paulo: analfabetismo e estigma. São Paulo. Dissertação [ Mestrado em Educação] Faculdade de Educação da Universidade de São Paulo; 2007. 